\title{
Hedges Function in Masculine and Feminine Feature's Language: A Pragmatics Analysis
}

\author{
Dinda Noor Azizah \\ Linguistics Program of Universitas Pendidikan Indonesia \\ E-Mail: dindanoor@upi.edu \\ DOI: https://doi.org/10.18326/jopr.v3i1.69-69
}

Copyright (C) The Author (s)

This work is licensed under a Creative Commons Attribution-ShareAlike 4.0 International License.

How to Cite: Azizah, D. (2021). Hedges Function in Masculine and Feminine Feature's Language: A Pragmatics Analysis. Journal of Pragmatics Research, 3(1). doi:https://doi.org/10.18326/jopr.v3i1.59-69

SUBMISSION
TRACK:
Received:
23-01-2021
Final Revision:
05-03-2021
Available online:
01-04-2021
Corresponding
Author:
Dinda Noor Azizah
dindanoor@upi.edu

\begin{abstract}
The purpose of this study is to criticize the gender language features proposed bs Coates (2013) proposed in Lakoff's theory (1975) by investigating speeches expressed by two different genders in interviews. The method used in this research is the descriptive qualitative method. Data were analyzed based on the theory oj Coates (2013) to find language features based on gender and use the taxonomy oj the hedging strategy proposed by Martin-Martin (2008). The results of the research show that male-female language features can be used by the opposite gender by looking at the perspective of the use of hedges and strategies in the concept of speech expressed by gender (male, female). Keywords: feature language; gender; hedges; hedging
\end{abstract}

\section{INTRODUCTION}

In social life, humans are surrounded by gender knowledge. In the field of linguistics, gender has become a variable in linguistic research. Holmes (2008) argues that the term gender is used to distinguish humans based on sociocultural behavior such as speech. Besides, Tong (2009) states that "there is a fact used by society as the foundation of constructing a masculine and feminine as gender identity" there is a difference between women's speech and men's speech. The relationship between gender and language has been a major issue in sociolinguistics since the early 1970s. Men and women have different speech styles. Lakoff (via Holmes, 2008 p.298) states that the differences in language use between men and women are morphologically different because women are more characterized by linguistic features or forms. In other words, the differences in men's and women's languages include vocabulary, voice, tone, style, and syntactic structure. In general, men's speech is considered logical, concise, and prioritizes important topics. Meanwhile, women are considered emotional, full of pleasantries, and talk at length. This statement is supported by Lakoff (1975) states that linguistic features are used more by women 
than men because women express uncertainty more often and have less confidence in conveying speech. Moreover, Lakoff explained that the linguistic feature often used by women is lexical hedges like you know, I mean, well. Most women more often use these linguistic features to express opinions. Lakoff supports this statement; he states that "women used more hedging and boosting devices than men." Hedges and boosting are linguistic features that are used to express a lack of confidence or show any expression of uncertainty or tentative sentences. (Lakoff, 1975 via Holmes, 2008, p. 299).

Women and men have different language features, Coates (2013) developed the theory of Lakoff (1975) about language features based on gender, Coates characterized women's language features including topic and topic development, minimal responses, hedges, tag questions, and jam session turn-taking model. Meanwhile, male language features include topic choices, monologues and playing the expert, questions, verbal sparring, and a one-at-at-time turn-taking model. In the use of hedges contained in female language features, Salager-Meyer (1997), describes hedges into several different grammatical forms, namely Auxiliary Verbs Model, Modal lexical verbs, Adjectival, adverbial, and nominal modal phrase, Approximator, Introductory phrases, If -clauses, and Compound hedges. All these taxonomies are used for ways of being more precise in reporting results. Hedging may present the true state of the writers' or speakers' understanding and may be used to negotiate an accurate representation of the state of the knowledge under discussion.

In this study, the focus of language features based on gender is Hedges. The linguists believe that gender influences the use of hedges. Coates (2013) states that hedges such as I think, You know, I'm sure, Sort of, Perhaps is a form of linguistics used to express uncertainty when speaking. Epistemic stance adverbials, including hedges, are related to the certainty, reliability, and limitation of propositional contents (Liu and Tseng, 2021). The new form that falls into the hedges classification is like, which is usually used by young English speakers. This is used by young speakers as a form of an effort to reduce speaking style. Lakoff (1975) states that hedges are "sounding of feminine" and reflect the position of women in society. Similar to Lakoff, Preisler (1986) argues that "linguistic tentativeness signals are correlated of both sex and interactional role, which is either task-oriented or socio-emotional". Preisler's data show that although women's language is characterized by the use of assertiveness strategies, this also includes the use of hedges.

However, Holmes (2008) has a different statement than Lakoff and Preisler's statement. Holmes (1995) stated that hedges are used by women as an act of politeness and solidarity with the interlocutor, rather than as a form of expressing uncertainty when delivering a speech. Holmes also argued that speakers use hedges in their speech to make it easier for the interlocutor to understand the speaker's meaning. He also revealed that women use hedges more often than men so that according to him, women are considered more supportive and polite. Also, Coates (2013) states "when talk does become more personal, it deals with matters such as drinking habits or 
personal achievements rather than feelings. Topic choice is not a superficial matter: it has profound consequences for other linguistic choices. Hedging, for example, is closely correlated with more personal and/or sensitive topics". In other words, unlike women, men will use hedges in their speech if the topic or context they are talking about is a matter of personal or sensitive matters.

As part of folk linguistics, it has been argued by linguists that women are more polite than men. To test this claim, it is necessary to know about politeness or politeness and how it occurs linguistically in different social lives. Brown and Levinson (1987) expressed two terms "face" as a form of politeness strategy, namely: Negative face as a form of freedom from action and freedom from interference, and Positive face as a form of desire to be appreciated by others and to maintain a positive self-image. Holmes (1995) indicates that although the politeness theory put forward by Brown and Levinson (1987) does not cover as broad as they claim, it is proven as a tool to investigate the pragmatic meaning and function of hedges. As is the case with other linguistics strategies, hedges can convey a lack of assertiveness but are also used to promote solidarity and as a negative politeness strategy (Tanaka, 2009). Brown and Levinson (1987) state that "hedges are particles, words, or phrases that modify the degree of membership of a predicate or a noun phrase in a set". According to previous studies, "the fuzzy hedges" was constructed by Lakoff, and the main point of hedges is some words that make things "fuzzy". In linguistics forms, hedges utilized as a modify a noun phrase or predicate subordinate relationship between expression (Wang, 2016). The function of hedges is to avoid making explicit statements and thus sound more polite. Hedging devices are useful in expressing opinions while softening them in the process (Almusaway, et al. 2019). Hedges utilized as a connect tools to the type of the conversation topic, to neutralize the sensitivity of the assertions ((Mohajer and Jan, 2015). The hedges forms can range from a single lexical item to syntactic structures, which do not ease the task of establishing a definition and hedges can appear alone or in clusters (Hassani and Razmdideh, 2019). The important thing of hedges lies in the fact that interlocutors expect claims to be warranted in terms of the assessments of reliability they carry, and appropriate in terms of the social interactions they appeal to (Hyland, 2000).

Martín-Martín (2008) describes the taxonomy of the hedges function in a socio-pragmatic study as a politeness strategy. He argues that it is unlikely that the hedges function will appear without considering the linguistic and contextual aspects of the situation. Martín-Martín (2008) classified the hedges function into three strategies, namely Strategy of Indetermination, Strategy of Subjectification, and Strategy of Depersonalization. In the use of language as a linguistic phenomenon, there are differences regarding gender. This phenomenon can be easily analyzed in 
daily conversations, interviews, or in a debate. In events involving the speech, several lexical hedges will appear. Therefore, the differences between women and men in speaking will appear in the linguistic features of each gender. On events that involve the speech, several lexical hedges will appear. Therefore, the differences between women and men in speaking will appear in the linguistic features of each gender.

To be used as references, some researchers have been conducted previously relates studies such as Wright and Hosman (1983) Language Style and Sex Bias in the Courtroom: The Effects of Male and Female Use of Hedges and Intensifiers On Impression Information illustrates that the sex of the witness was related to subjects' evaluations of their credibility and attractiveness when using hedges and when using intensifier. Mohajer and Jan (2015) in Preserving Face and the Use of Hedges in Masculine World of Men. The research finds that Iranian men try to protect their faces by inserting hedges and try to preserve the addresses' faces which is an indication of solidarity by using hedges feature in their interactions. Namaziandost and Shafiee (2018) in Gender Differences in the Use of Lexical Hedges in Academic Spoken Language among Iranian EFL Learners: A Comparative Study constructs that female student had a wide range variation in picking hedges in their speech while male students were not sufficiently productive in picking the hedges. Besides, Mirzapour (2016) in Gender Differences in the Use of Hedges and First Person Pronouns in Research Articles of Applied Linguistics and Chemistry illustrate the way male and female use hedges and first person pronoun in study of discourse of research article in Applied Linguistics and Chemistry. Also, Multifunction of Hedges Used by English Department Students: Gender Role Perspective by Kholisoh and Setiawan (2018) construct that men and women used hedges as a politeness strategy to express uncertainty and sustain interpersonal relationships and Based on the preliminary studies, regarding language features according to gender, namely, this research intends to find the functions of hedges in both men and women features language. The objectives of this research are utterances that conveyed in two videos of actors and actresses interviewing about career and personal life.

\section{RESEARCH METHOD}

The technique used in this data collection is document analysis, which is a systematic procedure for reviewing or evaluating documents in printed or electronic form Bowen (2009). This study used the descriptive qualitative method. The way to get data is by watching two videos on the Youtube channel First We Feast: Hot Ones with Halsey, as a female respondent and First We Feast: Hot Ones with Shawn Mendes, as a male respondent. First We Feast: Hot Ones is a show hosted by Sean Evans who interviews musicians and actresses about his career life. Then the data is analyzed and classified according to the language features of lexical hedges according to Salager-Meyer (1997) and the hedges strategy based on Martín-Martín (2008) from gender respondents in the two videos. 


\section{RESULTS \& DISCUSSION}

Table 5.1 .Lexical Hedges as Fillers

\begin{tabular}{lccc}
\hline & Features & Female & Male \\
Fillers & & 40 & 61 \\
Like & & 4 & - \\
Well & 14 & 4 \\
You know & 5 & 2 \\
Imean & & 2 & 3 \\
Probably & & 1 & 1 \\
Actually & & 5 & 22 \\
Just & Total & 71 & 93 \\
\hline
\end{tabular}

Table 5.2. Lexical Hedges as Lexical Verb

\begin{tabular}{lccc}
\hline & Features & Female & Male \\
\multicolumn{1}{l}{ It seems } & Lexical Verb & - & 1 \\
I think & & 2 & 4 \\
& Total & 2 & 5 \\
\hline
\end{tabular}

Table 5.3. Lexical Hedges as Modal Auxiliary Verbs

\begin{tabular}{lccc}
\hline \multicolumn{2}{c}{ Features } & Female & Male \\
\multicolumn{2}{c}{ Modal Auxiliary Verbs } & - & 1 \\
Would & & - & 1 \\
Could & & - & 2 \\
& Total & & \\
\hline
\end{tabular}

The number of female and male respondents who used lexical hedges was quite different. Total women expressed hedges as much as 73 hedges while men hedges as many as 100 hedges. Male respondents tend to use the lexical hedge in their speech. The following is a table that describes the tendency of Halsey $(\mathrm{H})$ as a female respondent and Shawn Mendes (SM) as a male respondent in using the hedges strategy in his speech which was taken from the video footage First We Feast: Hot Ones.

\section{Like}

Table 5.4. The use hedges 'like' in female respondent

\begin{tabular}{lll}
\hline H: “......kind of like twinkle or drops......." & \\
\hline Data & Hedges Strategy & Strategy Level Function \\
\hline like (adjective) & Indetermination & Approximator \\
\hline
\end{tabular}

Table 5.5. The use hedges 'like' in male respondent SM: “......You got to go to Vancouver, Victoria Island and you can rent a boat for like $\$ 45 \ldots . . .$.

\begin{tabular}{lll}
\hline Data & Hedges Strategy & Strategy Level Function \\
\hline like (adjective) & Indetermination & Approximator \\
\hline
\end{tabular}


In their speech, Halsey and Shawn Mendes used the word hedges 'like'. In this case, both respondents try to reduce the uncertainty in their speech so that it is accepted by listeners. The use of hedges 'like' is usually more often used by women to express a personal opinion or avoid a commitment. However, in this context, Halsey and Shawn Mendes describe hedges 'like' as an indetermination strategy that serves as an invitation to other people or listeners to agree with their speech and to indicate an unwillingness to make a proposition clearer and more comprehensive.

\section{Well}

Table 5.6. The use hedges 'well' in female respondent

$\mathrm{H}$ : "well...for us it's like a putting thing in a track"

\begin{tabular}{lll}
\hline Data & Hedges Strategy & Strategy Level Function \\
\hline well (adjective) & Subjectification & Introductory phrase \\
\hline
\end{tabular}

\section{You know}

Table 5.7. The use hedges 'you know' in female respondent

H: "I love Shawn Mendes, you know...."

\begin{tabular}{lll}
\hline Data & Hedges Strategy & Strategy Level Function \\
\hline you know (phrase) & Subjectification & Introductory phrase \\
\hline
\end{tabular}

Table 5.8. The use hedges 'you know' in male respondent

SM: “......I was obsessed with Youtube cover you know how people covering whatever top pop songs..."

\begin{tabular}{lll}
\hline Data & Hedges Strategy & Strategy Level Function \\
\hline you know (phrase) & Subjectification & Introductory phrase \\
\hline
\end{tabular}

In their speech, both respondents used hedges in the phrase 'you know'. In this case, both Halsey and Shawn Mendes try to get the audience's attention. Besides, they use hedges you know which have a level function of subjectification strategy to convince listeners to hear the truth from a proposition spoken by Halsey and Shawn Mendes by opening the listener's emotional state which aims to demonstrate the same knowledge.

\section{I mean}

Table 5.9. The use hedges 'I mean' in female respondent H: "...I mean it's supposed to involve some batches...."

\begin{tabular}{lll}
\hline Data & Hedges Strategy & Strategy Level Function \\
\hline I mean (phrase) & Subjectification & Introductory phrase \\
\hline
\end{tabular}

Table 5.10. The use hedges 'I mean' in male respondent

\begin{tabular}{|c|c|c|}
\hline Data & Hedges Strategy & Strategy Level Function \\
\hline Imean (phrase) & Subjectification & Introductory phrase \\
\hline
\end{tabular}

In their speech, both Halsey and Shawn Mendes use hedges in the phrase 'I mean'. Similar to the use of 'you know' hedges, in this case, both respondents try to grab the listener's attention. to convince listeners to believe the truth of a proposition put forward by both Halsey and Shawn Mendes.

\section{Probably}

Table 5.11. The use hedges 'probably' in female respondent

H: "Probably the funniest thing about New Jersey is the people...."

\begin{tabular}{lll}
\hline Data & Hedges Strategy & Strategy Level Function \\
\hline Probably (adjective) & Indetermination & Epistemic modality \\
\hline
\end{tabular}


Table 5.12. The use hedges 'probably' in male respondent

\begin{tabular}{lll}
\hline SM: "Yes it's probably true but it's annoying..." & \\
\hline Data & Hedges Strategy & Strategy Level Function \\
\hline Probably (adverb) & Indetermination & Epistemic modality \\
\hline
\end{tabular}

Both Halsey and Shawn Mendes use hedges 'probably' as a form of indetermination which functions as an epistemic modality. Both of them use this to cover up uncertainty in a proposition conveyed by each respondent.

\section{Actually}

Table 5.13. The use hedges 'actually' in female respondent

H: "I actually get nervous when my album came out..."

\begin{tabular}{lll}
\hline Data & Hedges Strategy & Strategy Level Function \\
\hline Actually (adverb) & Indetermination & Approximator \\
\hline
\end{tabular}

Table 5.14. The use hedges 'actually' in male respondent

\begin{tabular}{lll}
\hline SM: "I actually thought about it..." & \\
\hline Data & Hedges Strategy & Strategy Level Function \\
\hline Actually (adverb) & Indetermination & Approximator \\
\hline
\end{tabular}

Both Halsey and Shawn Mendes use hedges "actually" in their speech. As with hedges 'probably', both of them mention the word to cover up doubts in a sentence conveyed by both respondents.

Just

Table 5.15. The use hedges 'just' in female respondent H: “...my boyfriend and I just seeing each other...."

\begin{tabular}{lll}
\hline Data & Hedges Strategy & Strategy Level Function \\
\hline Just $($ adverb) & Interdetermination & Approximator \\
\hline
\end{tabular}

Table 5.16. The use hedges 'just' in male respondent SM: “....you just see the staff walking around...."

\begin{tabular}{lll}
\hline Data & Hedges Strategy & Strategy Level Function \\
\hline Just $($ adverb $)$ & Interdetermination & Approximator \\
\hline
\end{tabular}

In both Halsey and Shawn Mendes' speech, the use of the hedges' just 'is conveyed by both of them to shorten the proposition that both Halsey and Shawn Mendes uttered to cover up an unwillingness to say more.

\section{It seems}

Table 5.17. The use hedges 'It seems' in male respondent SM: "It seems fine"

\begin{tabular}{lll}
\hline Data & Hedges Strategy & Strategy Level Function \\
\hline It seems (phrase) & Depersonalization & Agentless passive \\
\hline
\end{tabular}

In the speech conveyed by Shawn Mendes, there is a hedge 'it seems' which indicates that the strategy is conveyed to reduce the variable existence of a proposition by using passive construction which aims to relieve the speaker from expressing more propositions in his speech. 


\section{I think}

Table 5.18. The use hedges 'I think' in female respondent

H: “...I think I've burnt away....”

\begin{tabular}{lll}
\hline Data & Hedges Strategy & Strategy Level Function \\
\hline Ithink (phrase) & Subjectification & Personal pronoun + cognitive verb \\
\hline
\end{tabular}

Table 5.19. The use hedges 'I think' in male respondent

\begin{tabular}{lcl}
\hline SM: “...I think I can't control anything....” & \\
\hline Data & Hedges Strategy & Strategy Level Function \\
\hline Ithink (phrase) & Subjectification & Personal pronoun + cognitive verb \\
\hline
\end{tabular}

The speech conveyed by both Halsey and Shawn Mendes is a strategy that aims to signal that what they are conveying is a subjective or personal opinion. With this hedges strategy, Halsey and Shawn Mendes indirectly engage listeners to be involved in the current communication situation.

\section{Would and Could}

Table 5.20. The use hedges 'would' in male respondent

SM: "She would like to expect burst..."

\begin{tabular}{lll}
\hline Data & Hedges Strategy & Strategy Level Function \\
\hline Would (word) & Indetermination & Epistemic modality \\
\hline
\end{tabular}

Table 5.21. The use hedges 'could' in male respondent

\begin{tabular}{lll}
\hline SM: “....the best thing I could do is pull random people" \\
\hline Data & Hedges Strategy & Strategy Level Function \\
\hline Could (word) & Indetermination & Epistemic modality \\
\hline
\end{tabular}

Hedges 'would' and 'could' conveyed by Shawn Mendes in this speech, he expressed his belief to do something. In other words, Shawn Mendes uses this strategy to provide an estimate on an aspect that will occur in a particular context.

Table 5.22. Recapitulation of the number of hedges strategies used by both genders

\begin{tabular}{lccc}
\hline \multirow{2}{*}{ Hedges Strategy } & Feminine & Masculine & \multirow{2}{*}{ Total } \\
\cline { 2 - 4 } & Frequencies & Frequencies & \\
\hline Indetermination & 48 & 89 & 137 \\
\hline Subjectification & 25 & 10 & 35 \\
\hline Depersonalization & - & 1 & 1 \\
\hline
\end{tabular}

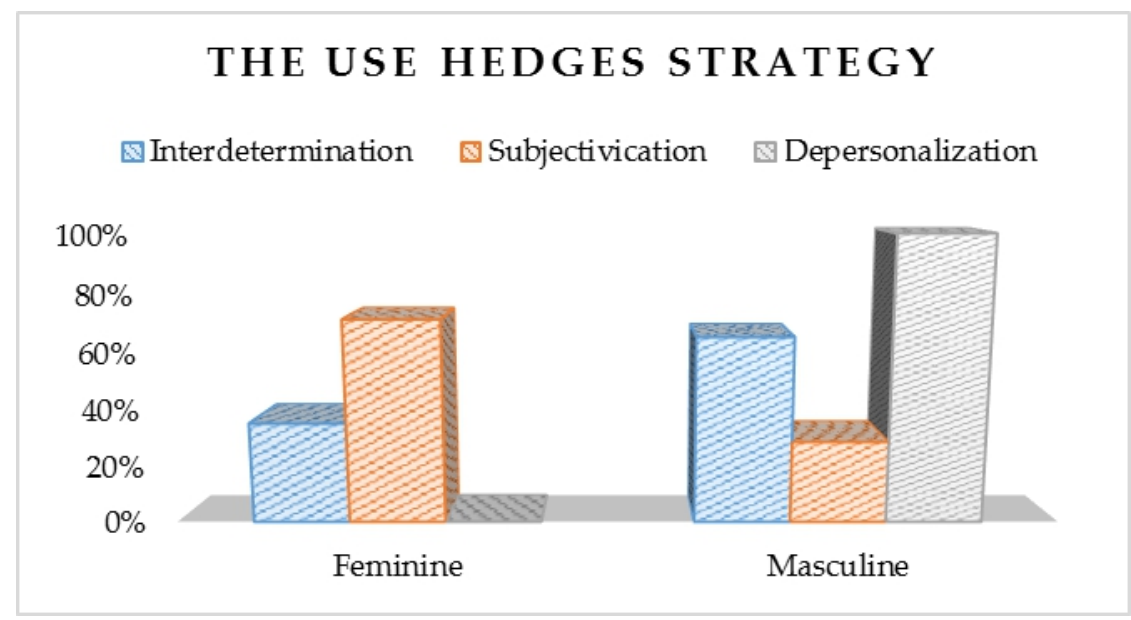

Figure 5.23. Percentage differences of the use of hedges strategy in two gender

Based on the analysis of the two First We Feast videos, it produces different trends and hedges strategies. Shawn Mendes as a male respondent tends to use hedges compared to Halsey as 
a female respondent. The two respondents used different hedges strategies with different frequencies. Shawn Mendes used Hedges indetermination strategy as much as 89 strategies, subjectification as much as 10 strategies, and depersonalization as much as one strategy. Meanwhile, Halsey used indetermination strategies as many as 48 strategies, subjectification as 25 strategies. Indetermination is the dominant strategy in the use of hedges in propositions, both expressed by Shawn Mendes and Halsey, to obscure a proposition to avoid face-threatening acts. Then, the hedges subjectification strategy ranks second in this case.

Subjectivation is used by both Shawn Mendes and Halsey. By using this strategy, speakers have a relationship with both positive politeness and negative politeness so that the content of the propositions spoken by the two genders is based on their beliefs and provides the opportunity for their listeners to participate in the chat. Furthermore, the depersonalization strategy was only spoken by Shawn Mendes. Using this strategy, Shawn Mendes ignores personal attributes in his proposition and engages the listener to participate in the proposition so that the proposition in his speech appears objective and acceptable to the listener. The constant use of hedges that conveyed by both participants is an indication of negative politeness strategies that aims to maintain the speaker's territory (Brown and Levinson, 1987 in Tanaka 2009).

\section{CONCLUSION}

Based on the results of the analysis and findings, it shows that men have a higher frequency than women in using hedges and their strategies. Although Lakoff (1975) and Coates (2013) state that hedges are a feature of women's language and Coates also states that men use hedges on personal or sensitive topics as described in the literature review section, in reality sometimes this does not happen. This is not only seen from the context of what is being discussed but other aspects such as the type of speech or the strategy for using hedges as discussed in this study. Thus, this study can conclude that the language features based on gender are not always based on the gender stereotype dimensions of the speakers themselves, in other words, men can use women's language features and vice versa by looking at the factors that influence it such as the strategies being used, voice quality or non-verbal cues, and the culture and environment that influence them. These factors can be used as a reference for further research. In addition to the features of the language of women hedges, other features of gendered language also need further research that can be discussed in relation to cultural differences, communities and so on. 


\section{REFERENCES}

Almusaway, E. R., Al-Hassnawi, H. D., Thamir, M. J., \& Info, A. (2019). Hedging in Interview Questions as a Politeness Strategy. Journal of University of Babylon for Humanities, 27.

Bowen, G. A. (2009). Document Analysis as a Qualitative Research Method. Qualitative Research Journal, 9(2), 27-40. https://doi.org/10.3316/QRJ0902027

Brown, P., \& Levinson, S. C. (1987). Politeness: Some Universals in Language Usage. New York: Cambridge University Press.

Coates, J. (2013). Women, Men and Language. London: Routledge.

First We Feast. (2018, 29 ${ }^{\text {th }}$ March). Shawn Mendes Reveals a New Side of Himself While Eating Spicy Wings - Hot Ones [Video]. YouTube. https://youtu.be/Oh4kio5hYn8 Retrieved on January, $20^{\text {th }} 2021$.

First We Feast. (2020, 27 $7^{\text {th }}$ February). Halsey Experiences the Jersey Devil While Eating Spicy Wings - Hot Ones [Video]. YouTube. https://youtu.be/TeMnMqPVRsw Retrieved on January, $20^{\text {th }} 2021$.

Hassani, M., \& Razmdideh, P. (2019). The Effect of Gender and Style Variables on Hedging Devices among Persian Speakers. International Journal of Applied Linguistics and English Literature, 8(3), 130. https://doi.org/10.7575/aiac.ijalel.v.8n.3p.130

Holmes, J. (1995). Women, Men and Politeness. New York: Routledge.

Holmes, J. (2008). An Introduction to Sociolinguistics. London: Routledge.

Hyland, K. (2000). Hedges, Boosters and Lexical Invisibility: Noticing Modifiers in Academic Texts. Language Awareness, 9(4), 179-197. https://doi.org/10.1080/09658410008667145

Kholisoh, N. N., \& Setiawan, S. (2018). Multifunction of Hedges Used by English Department Students: Gender Role Perspective. 2nd Social Sciences, Humanities, and Education Conference (SoSHEC 2018) Multifunction, 222. https://doi.org/10.2991/soshec-18.2018.46

Lakoff, R. (1975). Language and Woman's Place. London: Harper \& Row Publisher.

Lakoff, R. (1977). What You Can Do With Words: Politeness, Pragmatics, and Performatives. Proceedings of the Texas Conference on Performatives, Presuppositions and Implicatures, 79-106.

Liu, C., \& Tseng, M. Y. (2021). Paradigmatic Variation in Hedging and boosting: A Comparative Study of Discussions in Narrative Inquiry and Grounded Theory Research. English for Specific Purposes, 61, 1-16. https://doi.org/10.1016/j.esp.2020.08.002

Martín-Martín, P. (2008). The Mitigation of Scientific Claims in Research Papers: A Comparative Study. IJES, 8(2), 133-152. www.um.es/ijes 
Mirzapour, F. (2016). Gender Differences in the Use of Hedges and First Person Pronouns in Research Articles of Applied Linguistics and Chemistry. International Journal of Applied Linguistics and English Literature, 5(6), 166-173.

https://doi.org/10.7575/aiac.ijalel.v.5n.6p.166

Mohajer, L., \& Jan, J. M. (2015). Preserving Face and the Use of Hedges in Masculine World of Men. Procedia - Social and Behavioral Sciences, 208, 13-20.

https://doi.org/10.1016/j.sbspro.2015.11.176

Namaziandost, E., \& Shafiee, S. (2018). Gender Differences in the Use of Lexical Hedges in Academic Spoken Language among Iranian EFL Learners: A Comparative Study.

International Journal of Research in English Education, 3(4), 63-80.

https://doi.org/10.29252/ijree.3.4.63

Preisler, B. (1986). Linguistic Sex Roles in Conversation: Social Variation in the Expression of Tentativeness in English. Language in Society, 18(2), 293-299.

Salager-Meyer, F. (1997). I Think That Perhaps You Should: A Study of Hedges in Written Scientific Discourse. Functional Approaches to Written Text: Classroom Applications, 105118.

Tanaka, L. (2009). Communicative stances in Japanese interviews: Gender differences in formal interactions. Language and Communication, 29(4), 366-382.

https://doi.org/10.1016/j.langcom.2009.03.001

Tong, R. (2009). Feminist Thought: A More Comprehensive Introduction. Colorado: Westview Press.

Wang, Y. (2016). Research on Hedges in English News Reports. 4th International Conference on Management Science, Education Technology, Arts, Social Science and Economics (MSETASSE 2016), 85. https://doi.org/https://doi.org/10.2991/msetasse-16.2016.314

Wright, J. W., \& Hosman, L. A. (1983). Language Style And Sex Bias in The Courtroom: The Effects Of Male and Female Use of Hedges and Intensifiers on Impression Information. Southern Speech Communication Journal, 48(2), 137-152. https://doi.org/10.1080/10417948309372559 